\title{
LIPIDS OF HUMAN TESTES REMOVED AT ORCHIDECTOMY
}

\author{
J. G. GONIGLIO, W. M. GROGAN, JR AND R. K. RHAMY \\ Department of Biochemistry and Division of Urology, \\ Department of Surgery, Vanderbilt University School of Medicine, Nashville, \\ Tennessee 37232, U.S.A.
}

(Received 3rd December 1973)

\begin{abstract}
Summary. Lipid and fatty acid analyses have been made on the testes of sixteen human subjects obtained at orchidectomy. About $60 \%$ of the total lipid was phosphatide, $12 \%$ triglyceride, $6 \%$ free cholesterol and $2 \%$ esterified cholesterol. Phosphatidyl choline was the chief phosphatide present, followed by phosphatidyl ethanolamine. Other phosphatides were phosphatidyl serine, phosphatidyl inositol and sphingomyelin. The major saturated fatty acids found in the total lipids were palmitic and stearic while the major monoenoic acid was oleic. A 20-carbon triene of the linoleic acid family (20:3 w6) was present in significant quantities together with arachidonate and 22:6 w3. Only small amounts of 22:5 were present and isomers of both the linoleic and linolenic acids were present in this fraction. Histological studies revealed active spermatogenesis in over $50 \%$ of the testes analysed. In five cases with marked tissue degeneration, the concentration of total phosphatides was lower than in the other samples. In four of these, the concentration of 22:6 was lower than in the other samples. It is suggested that this polyenoic acid may be associated with the testicular germinal cells.
\end{abstract}

\section{INTRODUCTION}

Knowledge of the lipid composition of the reproductive organs is essential in order to understand the rôle of lipids in reproductive biology. Since it is not safe to extrapolate from other animals to man without proper supporting data, it is important that lipid studies be carried out on human tissue whenever possible. It is for this reason that this laboratory is engaged in studies of the lipid composition and metabolism in human testes which become available. Because the lipid composition is expected to vary with age (Davis, Bridges \& Coniglio, 1966) and may vary with spermatogenic activity, the histological conditions of such organs must be assessed at the time of lipid analysis. One of the abundant sources of testes for laboratory study is tissue obtained at orchidectomy for prostatic cancer. This paper presents data on the lipid composition of testes removed at orchidectomy and an evaluation of their histological state. The analytical results are compared with data on human tissue reported by 
Bieri \& Prival (1965) and with data obtained on adult rat testes (Davis et al., 1966).

\section{MATERIALS AND METHODS}

The sixteen patients were between the ages of 60 and 81 years (mean age, 69) with the exception of one 50- and one 58-year-old man. Orchidectomy was performed for prostatic cancer, but the testes were not involved. In the rare instances when the testes were grossly atrophic, they were not included in the study. The organs were placed directly in ice by the surgeon and taken immediately to the lipid laboratory for analysis. In most cases, analyses were started within $1 \mathrm{hr}$ of the removal of the organ, during which time the testes were kept immersed in ice. After a section had been removed for histological examination, part of the tissue ( 2 to $3 \mathrm{~g}$ ) was homogenized in Folch mixture and part (1 to $2 \mathrm{~g}$ ) was hydrolysed with alcoholic potassium hydroxide for total fatty acid separation. The histological sections were fixed in Bouin's fluid and stained with periodic acid-Schiff stain (PAS) and counterstained with Wright's iron-haematoxylin. Spermatogenesis was assessed on a scale from zero to $4+$ after examination of a series of sections. Hydrolysis of the tissue and extraction of the fatty acids were carried out by the methods reported previously (Bridges \& Coniglio, 1970). Methyl esters were prepared by the method of Metcalfe \& Schmitz (1961), and duplicate analyses were carried out by gas chromatography (Bridges \& Coniglio, 1970). Standard methyl esters obtained from the Hormel Institute (University of Minnesota, Austin, Minnesota) and Applied Science Laboratories, Inc. (State College, Pennsylvania) were used for calibration of the detector. Methyl esters were hydrogenated (Farquhar, Insull, Rosen, Stoffel \& Ahrens, 1959) and the hydrogenated derivatives were analysed by gas chromatography to establish the total amount of fatty acids of a particular chain length. These determinations helped in the identification and quantification of the complex mixtures of fatty acids obtained. Further identifications were made by comparison with known standards. For chemical identification of $8,11,14$ eicosatrienoic acid, the fatty acid was isolated in pure form by gas chromatography and subjected to procedures of oxidative ozonolysis (Stoffel, 1965) and u.v. spectrophotometry following alkaline isomerization (Holman \& Hayes, 1957).

Aliquots of total lipids obtained by extraction with Folch reagent were used for determinations of phospholipid phosphorus (Doizaki \& Zieve, 1963), triglycerides (Sardesai \& Manning, 1968), and free and esterified cholesterol (Sperry \& Webb, 1950), after separation by thin-layer chromatography on Adsorbosil 2 (Applied Science Laboratories) using the solvent system petroleum ether ( 80 vols), diethyl ether $(20$ vols $)$ and glacial acetic acid ( 1 vol. $)$. The factor 25 was used to convert $\mathrm{mg} P$ to $\mathrm{mg}$ phosphatides. Individual phosphatides were separated by thin-layer chromatography on glass plates coated with Supelcosil 42 A (Supelco, Inc., Bellefonte, Pennsylvania) with the one-dimensional system: chloroform $/$ methanol $/ 28 \%$ ammonia ( $65 / 25 / 5$ by vol.) or on glass plates coated with Silica Gel HR (product of Merck and Co., Darmstadt, Germany, supplied by Applied Science Laboratories, State College, Pa.), using the one- 
dimensional system: chloroform/methanol/28\% ammonia (65/25/4 by vol.). After developing and charring lightly with sulphuric acid, the identified spots were scraped quantitatively into test-tubes and phosphorus was quantified by the method of Doizaki \& Zieve (1963). All analyses of lipid fractions were carried out at least in duplicate.

\section{RESULTS}

The results of the analyses of the total lipid in the testes from the sixteen patients are shown in Table 1. Most of the total lipid was phosphatide (about $60 \%$ )

Table 1. Lipid composition of human and rat testes

\begin{tabular}{|c|c|c|c|}
\hline Lipid classes & $\begin{array}{l}\text { Human testes } \\
\text { removed at } \\
\text { autopsy* }\end{array}$ & $\begin{array}{l}\text { Human testes } \\
\text { removed at } \\
\text { orchidectomy } \dagger\end{array}$ & $\begin{array}{c}\text { Adult rat } \\
\text { testes } \\
\dagger\end{array}$ \\
\hline & \multicolumn{3}{|c|}{$\mathrm{mg} / \mathrm{g}$ wet wt of tissue } \\
\hline $\begin{array}{l}\text { Total lipid } \\
\text { Total phosphatides } \\
\text { Glycerides } \\
\text { Free cholesterol } \\
\text { Esterified cholesterol }\end{array}$ & $\begin{array}{c}15 \cdot 9 \pm 0 \cdot 9 \\
8 \cdot 9 \pm 0 \cdot 7 \\
= \\
3 \cdot 4 \pm 0 \cdot 2\end{array}$ & $\begin{array}{l}24 \cdot 4 \pm 0 \cdot 98 \\
14 \cdot 7 \pm 0 \cdot 87 \\
2 \cdot 84 \pm 0 \cdot 26 \\
1 \cdot 40 \pm 0 \cdot 06 \\
0 \cdot 56 \pm 0 \cdot 05\end{array}$ & $\begin{array}{c}24 \cdot 2 \\
15 \cdot 0 \\
0.95 \\
1 \cdot 8 \\
0 \cdot 8\end{array}$ \\
\hline Phosphatide classes & \multicolumn{3}{|c|}{$\%$ of total phosphatides } \\
\hline $\begin{array}{l}\text { Phosphatidyl choline } \$ \\
\text { Phosphatidyl ethanolamine } \$ \\
\text { Phosphatidyl serine } \\
\text { Phosphatidyl inositol } \\
\text { Sphingomyelin }\end{array}$ & & $\begin{array}{l}48 \cdot 3 \pm 2 \cdot 27 \\
22 \cdot 3 \pm 2 \cdot 81 \\
7 \cdot 42 \pm 0 \cdot 96 \\
6 \cdot 64 \pm 0 \cdot 33 \\
8 \cdot 28 \pm 0 \cdot 65\end{array}$ & $\begin{array}{c}44 \cdot 6 \\
25 \cdot 8 \\
5 \cdot 6 \\
\text { Not reported } \\
6 \cdot 3\end{array}$ \\
\hline
\end{tabular}

* Data of Bieri \& Prival (1965).

+ Mean of sixteen samples + S.E.M.

† Calculated from data of Davis, Bridges \& Coniglio (1966).

$\$$ Includes the plasmalogen fraction.

while about $12 \%$ was glyceride (essentially all triglyceride), $6 \%$ was free cholesterol and about $2 \%$ was esterified cholesterol.

The fatty acid pattern of the total fatty acid fraction of the testes is given in Table 2 as a percentage of the total fatty acids. The major saturated fatty acids were palmitic $(16: 0$, i.e. no. of carbon atoms in chain: no. of double bonds) and stearic (18:0) and the major monoenoic acid was oleic (18:1). The major trienoic acid found was 8,11,14 eicosatrienoic (20:3 w6). The major polyenoic acid was 20:4 (arachidonic acid) while the major 22-carbon fatty acid was 22:6 w3. Only small amounts of 22:5 were present, but isomers of both the linoleic acid family $(22: 5 \mathrm{w} 6)$ and the linolenic acid family $(22: 5 \mathrm{w} 3)$ were present.

Table 3 presents the results of a comparison of the fatty acid composition of hydrogenated total fatty acids with that obtained by calculation from values given in Table 2. In general, agreement was satisfactory. From the analysis of the hydrogenated samples, it is evident that the tissue contained 24-carbon compounds which could not be measured in the non-hydrogenated samples 
because the individual concentrations were too low and the retention times too long. In addition, evidence was obtained in some of the hydrogenated samples that traces of 26-carbon fatty acids were present.

Over $50 \%$ of the testes showed active spermatogenesis (1 to $4+)$ without significant atrophy. In these testes, there was good to excellent production of primary and secondary spermatocytes with normal quantities of spermatozoa

Table 2. Major fatty acid composition of human and rat testes

\begin{tabular}{|c|c|c|c|}
\hline Fatty acid & $\begin{array}{l}\text { Human testes removed } \\
\text { at orchidectomy } \dagger\end{array}$ & $\begin{array}{l}\text { Human testes } \\
\text { removed at autopsy* }\end{array}$ & $\begin{array}{c}\text { Adult rat } \\
\text { testes } \$\end{array}$ \\
\hline $\begin{array}{l}14: 05 \\
16: 0 \\
16: 1 \\
18: 0 \\
18: 1 \\
18: 2 \\
20: 3 \\
20: 4 \\
22: 5 \\
22: 6\end{array}$ & $\begin{array}{l}1.62 \pm 0.17 \\
32.9 \pm 0.83 \\
2.98 \pm 0.25 \\
10.7 \pm 0.63 \\
19 \cdot 6 \pm 1.37 \\
5.44 \pm 0.69 \\
4.88 \pm 0.37 \\
11.5 \pm 0.64 \\
0.69 \pm 0.21 \\
6.35 \pm 0.45\end{array}$ & $\begin{array}{c}\text { Not reported } \\
27 \cdot 8 \pm 0.9 \\
3.6 \pm 0.4 \\
11.8 \pm 0.6 \\
16.4 \pm 1 \cdot 3 \\
5.6 \pm 0.3 \\
6.7 \pm 0.4 \\
13.4 \pm 0.6 \\
0.4 \pm 0.1 \\
8.5 \pm 0.7\end{array}$ & $\begin{array}{c}\text { Not reported } \\
36.1 \\
\text { Not reported } \\
4.9 \\
13.5 \\
6.1 \\
\text { Not reported } \\
18.0 \\
19.6 \\
\text { Not reported }\end{array}$ \\
\hline
\end{tabular}

Values are given as $\%$ of total fatty acids.

* Data of Bieri \& Prival (1965).

$\dagger$ Mean of sixteen samples \pm S.E.M.

$¥$ Galculated from data of Davis et al. (1966).

$\$$ No. of carbons in chain: no. of double bonds.

Table 3. Fatty acid composition of hydrogenated total fatty acids of human testes removed at orchidectomy

\begin{tabular}{c|c|c}
\hline $\begin{array}{c}\text { Fatty } \\
\text { acid }\end{array}$ & $\begin{array}{c}\text { Determined by gas chromato- } \\
\text { graphic analysis of hydro- } \\
\text { genated sample }\end{array}$ & $\begin{array}{c}\text { Calculated from } \\
\text { data in Table } 2\end{array}$ \\
\hline $14: 0$ & $2 \cdot 1$ & $1 \cdot 6$ \\
$16: 0$ & $33 \cdot 6$ & $35 \cdot 9$ \\
$18: 0$ & $35 \cdot 3$ & $35 \cdot 7$ \\
$20: 0$ & $18 \cdot 6$ & $16 \cdot 4$ \\
$22: 0$ & $8 \cdot 4$ & $7 \cdot 1$ \\
$24: 0$ & $1 \cdot 0$ & Not determined \\
$26: 0$ & Trace & Not determined \\
\hline
\end{tabular}

Values are given as $\%$ of total fatty acids.

within the lumina of the tubules. The five patients out of the sixteen which manifested the most marked testicular atrophy had undergone previous therapy with oestrogens for at least 6 months. Their testes were rated zero in the 0 to $4+$ scale for spermatogenesis. Lipid analyses for this group revealed that only the mean \pm S.E.M. value for total phospholipid was significantly different from that for the entire group $(11.9 \pm 1.3$ versus $14.7 \pm 0.87)$. The mean value for 22:6 was lower for this group than for the entire group of sixteen patients 
$(5 \cdot 34 \pm 0 \cdot 70$ versus $6 \cdot 35 \pm 0 \cdot 45)$ but the difference was not quite statistically significant $(P=0 \cdot 15)$.

Similar calculations were made for five of the patients who were more than 70 years old (i.e. $76,77,77,79,81$ ) but the averages for this group were not significantly different from those for the sixteen patients for any of the lipid or fatty acid analyses.

\section{DISCUSSION}

The sum of the lipid fractions shown in Table 1 for the human tissues obtained at orchidectomy was lower than the result obtained gravimetrically for total lipid. This was due, at least in part, to pigments present in the tissue. It is possible that hydrocarbon-type compounds were also present, but this was not investigated further and at present we have no explanation for the remaining discrepancy. These data may be compared with those reported by Bieri \& Prival (1965) on five human accident victims (ages not reported) and with data published previously from our laboratory on adult rats maintained on a stock diet (Davis et al., 1966), as shown in Table 1. We obtained larger quantities of total lipid than did Bieri \& Prival (1965) and the amounts found in our human samples were not significantly different from the amounts we reported in rats. The different methods used may explain the discrepancy in the results obtained by Bieri \& Prival and those obtained by us. Total lipid determinations in our laboratory were carried out by gravimetric analysis of a purified Folch extract while those of Bieri \& Prival were achieved by a chromic acid oxidation. We also found a greater amount of total phosphatides than did Bieri \& Prival and these amounts were similar to those found in rats. Our results for cholesterol concentrations were slightly lower than those of Bieri \& Prival and were similar to the results obtained on rats. Whether the ages of the subjects have a bearing on the differences in results between these two studies cannot be determined because the ages of the subjects of Bieri \& Prival were not reported. In our studies, the lipid values of the group of men aged 70 to 81 were not significantly different from those of the younger group aged 50 to 69 . The youngest person in our group was 50 years old, and the lipid values for samples from this patient were not unlike those for others in the group. A further difference between the two studies was that while we analysed fresh tissue, the tissues analysed by Bieri \& Prival were obtained at autopsy. The results reported by Bieri \& Prival on rat testes were not very different from ours except for their lower total lipid value. These authors did not report values for the various phosphatide classes but our values for men did not differ greatly from those obtained previously on rats (Table 1). The largest fraction in the phosphatide group was phosphatidyl choline, followed by phosphatidyl ethanolamine. As determined in our present analyses, both these values would include plasmalogens which are present in these tissues, but we do not have separate determinations of the plasmalogens. Not all the classes of phosphatides were determined in these samples. Lysophosphatidyl choline was present in small amounts and about 8 to $10 \%$ of the phosphatides were unidentified.

Our studies revealed a difference in polyenoic fatty acids between rat and 
man. The orchidectomy data are not very different from those reported by Bieri \& Prival for human tissue obtained at death but their values for $20: 3$, 20:4 and 22:6 acids were slightly greater than ours (Table 2). The data reported previously by Davis $e t$ al. (1966) for the testes of adult rats agree satisfactorily with data for rat tissue reported by Bieri \& Prival (1965). The major differences between rat and man are the higher concentrations of 18:0, 20:3 and 22:6 and the lower concentration of $20: 4$, and particularly of $22: 5$, in human testis.

Bieri \& Prival identified the 20:3 w6 in human tissue on the basis of retention time. We confirmed this and established the identity of the isomer by chemical analysis of the isolated pure methyl ester (Grogan, Coniglio \& Rhamy, 1973). Rat testes have only traces of this fatty acid.

The results of the fatty acid analyses of the hydrogenated samples provide support for the results obtained on the non-hydrogenated samples. The complexities of these mixtures often result in peaks which are difficult to identify and to quantify, e.g. the very long chain polyenes. Analyses of hydrogenated samples show conclusively that human testes have 24-carbon polyenes as has been shown for rat tissues (Bridges \& Coniglio, 1970) but we do not yet know whether these are the same polyenes as those encountered in the rat. In some hydrogenated samples, small amounts of a compound emerging with a retention time equal to that of 26:0 were observed, but the presence of 26-carbon compounds in human testes as well as in rat testes has yet to be proved conclusively. Whereas rat testes accumulate 22:5 w6, a derivative of linoleic acid, human testes accumulate 22:6w3, a derivative of linolenic acid. The rooster is known to accumulate $22: 4 \mathrm{w} 6$ in the testes. Why different polyenoic acids are accumulated by testes of different species is a problem yet to be solved. In the rat, it has been suggested that the increase in the concentration of testicular 22:5 w6 is associated with the appearance and development of spermatids and spermatozoa (Davis \& Coniglio, 1967).

In general, little variation was found in lipid and fatty acid composition with different degrees of testicular degeneration (except for total phosphatide concentration). Although no statistical significance could be ascribed to the difference in concentration of the polyenoic acid, $22: 6$, between the group with most marked testicular degeneration and the other subjects, a lower concentration was observed in four of the five patients with most marked atrophy. One patient with well-preserved germinal epithelium had a low $22: 6$ level $(3.2 \%)$, a low $20: 3$ level $(3 \cdot 1 \%)$ but a high $20: 4$ concentration $(12 \cdot 3 \%)$. The others had values in the range of 6.7 to 9.7 for $22: 6$ concentration.

The total phosphatide concentration generally paralleled the $22: 6$ concentration with only minor exceptions. The highest 22:6 levels were found in testes with phosphatide concentrations of over $60 \%$ of total lipids, while the lowest $22: 6$ concentrations occurred in testes with phosphatide levels of about $50 \%$ of total lipids. Similar correlations were apparent with the concentration of phosphatidyl ethanolamine. We have determined the concentration of 22:6 in the testes of two infants ( 2 and 3 days old) obtained at autopsy to be less than $1 \%$. In both infants, the phosphatide concentration was about $40 \%$ of the total lipid. It is suggested that certain polyenoic acids (particularly those in phosphatides) may be associated with germinal elements. More specific 
information has to await the analysis of many more samples and the separation of cell types for subsequent analysis. In other tissues, such as the heart and brain, the phosphatidyl ethanolamine fraction of the phosphatides is especially enriched with 22:6. Pursel \& Graham (1967) reported a high concentration of 22:6 in the choline phosphatides of bull spermatozoa. In our experiments, the fatty acid composition of the individual phosphatide classes has not yet been determined.

\section{ACKNOWLEDGMENTS}

The authors acknowledge the excellent technical assistance of Mr Ted Myron Bryant and Mr Ted L. Rozell, Jr, and the preparation of the histological sections by Mr R. F. Sellers, Department of Anatomy. This work was supported by Research Grant 5 ROI HD 06070 from the U.S. Public Health Service.

\section{REFERENCES}

Bieri, J. G. \& Prival, E. L. (1965) Lipid composition of testes from various species. Comp. Biochem. Physiol. 15, 275.

BRIDGEs, R. B. \& Coniglio, J. G. (1970) The biosynthesis of $\Delta^{9,12,15,18}$ tetracosatetraenoic and of $\Delta^{6,9,12,15,18}$ tetracosapentaenoic acids by rat testes. 7 . biol. Chem. 245, 46 .

Davis, J. T., Bridges, R. B. \& Coniglio, J. G. (1966) Changes in lipid composition of the maturing rat testis. Biochem. 7. 98, 342.

DAvis, J. T. \& Coniglio, J. G. (1967) The effect of crytorchidism, cadmium, and anti-spermatogenic drugs on fatty acid composition of rat testis. F. Reprod. Fert. 14, 407.

DoIZAKI, W. M. \& ZIEvE, L. (1963) Quantitative estimation of some phosphatides and their hydrolysis products by thin-layer chromatography. Proc. Soc. exp. Biol. Med. 113, 91.

Farquhar, J. W., Insuld, W., JR, Rosen, P., Stoffer, W. \& Ahrens, E. H., JR (1959) The analysis of fatty acid mixtures by gas-liquid chromatography. Nutr. Rev. 17, Suppl. 2.

Grogan, W. M., JR, Coniglio, J. G. \& Rhamy, R. K. (1973) Identification of some polyenoic acids isolated from human testicular tissue. Lipids, 8, 480.

Holman, R. T. \& Hayes, H. (1957) Measurement of polyunsaturated fatty acids. Meth. biochem. Analysis, 4, 499.

Metcalfe, L. D. \& Schmitz, A. A. (1961) The rapid preparation of fatty acid esters for gas chromatographic analysis. Analyt. Chem. 33, 363.

Pursel, V. G. \& Graham, E. F. (1967) Phospholipids of bovine spermatozoa and seminal plasma. $\mathcal{F}$. Reprod. Fert. 14, 203.

SARdesai, V. M. \& Manning, J. A. (1968) The determination of triglycerides in plasma and tissues. Clin. Chem. 14, 156.

SPERRY, W. M. \& WEBB, M. (1950) A revision of the Schoenheimer-Sperry method for cholesterol determination. 7. biol. Chem. 187, 97.

Stoffel, W. (1965) Chemical synthesis of $\mathrm{H}^{3}$ and I-G $\mathrm{C}^{14}$-labeled polyunsaturated fatty acids. $\mathcal{F} . \mathrm{Am}$. Oil Chem. Soc. 42, 583. 